\title{
Design Gamification Models in Higher Education: A Study in Indonesia
}

\author{
https://doi.org/10.3991/ijet.v15i12.13965 \\ Isabel Coryunitha Panis \\ Universitas Negeri Malang, Malang, Indonesia \\ Universitas Katolik Widya Mandira, Kupang, Indonesia \\ fegyjama@yahoo.com \\ Punaji Setyosari, Dedi Kuswandi, Lia Yuliati \\ Universitas Negeri Malang, Malang, Indonesia
}

\begin{abstract}
Based on the data, it is known that the average score from the evaluation aspects of the learning design reached in the very good category. This figure according to the results of the conversion from quantitative data to qualitative data, which means that the learning design of gamified problem-based learning developed is feasible to be applied in learning. The purpose of writing this article is to develop an appropriate gamification model in tertiary institutions which links gamification theory and problem- based learning into a new model that will later be combined with existing learn- ing media to become more effective and interesting when applied in each course. Research on learning design models can be classified into three types: model development, model validation, and model use. This study discuses two points above, which are based on research methodologies for model development and model validation where learning models are developed either practically or theoretically. In theory, the cause is based on the literature related to the model that is to be developed, being practical because it must be based on a learning design that is suitable for real life. The gamified problem-based learning design model has been based on literature and has projected real-life learning needs. In the results, it is known that the effectiveness and attractive- ness of the design of gamified problem-based learning as teaching material in the form of theory and practice have shown results in the excellent category which means that this learning design is feasible to be applied in learning.
\end{abstract}

Keywords-Design, Gamification, Model, Higher Education, Indonesia

\section{$1 \quad$ Introduction}

The definition of learning gamification, according to [1] said as an alternative in the process of motivating and able to reach the demand for the need for learning experiences to form appropriate learning characteristics as a result. The same thing about gamification was also revealed by [2] about the advantages of the gamification strate$\mathrm{gy}$, which has its appeal because it can reduce one's emotional level. It said that learn- 
ing that arises from a desire could influence the idea of students' behaviour, and that influence will also affect the emotional strength of students.

The selection of gamification as one of the strategies in learning, emphasizes the occurrence of a misconception between explanation and understanding of the concept of material from educators to students so that it becomes a new goal for researchers in developing appropriate gamification models in higher education. In [1] said, learning based on the application of gamification will make a difference which will form different learning outcomes. The application of gamification in learning seen to be able to have a positive influence in improving cognitive abilities and student achievement

[3] is consider necessary because based on opinions [4] found research that can meas- ure the effectiveness of learning and teaching improvement projects involving the use of games and the gamification process using modules media theory in students. On the other hand, by effectively applying gamification in learning can influence students' critical thinking processes dominantly.

This view can be used as a breakthrough in education when the application of gamification as a strategy by mixing and matching to the Problem-based learning (PBL) model as a syntax in learning, especially specifically in learning Physics. The research that has existed in the physics study program it founded several studies that use gamification as a strategy or gamification as a medium that can increase students' motivation and learning behaviour in learning.

Issues regarding education systems and strategies in Indonesia are currently in line with the results of the initial observations of researchers and some of the results of research on students in the physics education study program, in basic physics courses. Found fundamental problems experienced by students in the Physics study program, which must solve with the right solution.

Several problems were found. In this study: The first problem; students are still dependent on the rote system, which causes a lack of understanding of the learning concepts presented by educators. For example, in mentioning the Physics formula, there are still stuttering learners in pronouncing it. After exploring, the basic problem is not to the level of understanding the formula but limited to memorizing the formula and not understanding the concept of the formula presented. The same problem is that Physics courses considered to be elusive subjects so that it has a direct impact on the acquisition of low student scores, therefore according to research [5] revealed by improving conducive learning atmosphere according to the gamification approach can increase student learning motivation.

The second problem; learners speak at a normative mathematical level while the physics is not. Students are usually not encouraged to ask questions and use their imagination, raise their problems, look for answers to problems or show many initiatives.

The third problem, changes in thinking are still very low. The understanding concepts of gamified problem based and the application of students' learning concepts, limited to learning resources such as reading books, and information from educators.

The fourth problem, in the field, learning media, has not been maximized in the learning process. Learning media available and often used in the form of textbooks, videos and presentation files are still one-way. 
Gamification strategy can add to the learning experience, and make students better recognize and understand the learning material presented which is based on the discovery of learning problems in general and specifically in the classroom [6].

Analysis [6] reveals that fundamental dynamics will have a direct impact on gamification strategies so that they are recognized and used in modern pedagogical practices. The legitimacy of the practice of gamification which considered shallow be- cause of the fact, this gamification strategy provides a useful way and guidance with the power of the game to motivate students in achievement.

The learning gamification strategy was chosen as the focus of the study because gamification has an important role in achieving the learning success of students. In teaching and learning activities, the unclear material presented can be helped by using the media as an intermediary. On the other hand, the gamification learning strategy uses game dynamics, mechanics, and frameworks to non-game settings. The implementation of gamification strategies in this study, as a form of reference for educators in understanding and effectively using gamification strategies to improve student learning outcomes [6].

\section{Relevant Literature}

\subsection{Definition of gamification in learning}

The term gamification or "gamification" appears to have been coined in 2002 by Nick Pelling, with the first documented printed appearance in 2008. However, the term did not gain widespread recognition until 2010 [7]. While the term is relatively new, there seems to be a general agreement on the basic principles of gamification. Gamification has fined as a process by using the mindset of games and "machines" as a tool in attracting interest and solving any educational problems, even other notions of gamification itself as a technique in capturing the attention of students and making learning more enjoyable even gamification can also be used by using elements that contained in the context of the game [7].

Most of the research in international journals deal with gamification using IT tools. In [8] researching the effect of gamification using personalized learning that utilizes analytic learning on learning outcomes. Gamification used is to use online learning media.

Some research states that to achieve results, the use of gamification must go through several stages of evaluation and reflection of the process that previously car- ried out. Some recommendations that can be used by researchers who are interested in doing learning design using gamification include [9]: 1) focus on students, 2) use only one or a few game mechanics that are approximately following the circumstances, 3) do not make technology as the main thing in the development of gamification, 4) do not rely too much on the results of analytic learning, because it can be misleading if used improperly, 5) always make revisions and repetitions to get the maximum, 6) make the learning atmosphere into an interesting and happy game for the teacher and students. Implementing an approach using gamification requires more effort, but students will 
feel more involved and happy in learning. However, the teacher has a very big role as a designer of learning activities, and there will be no one who can replace it (Mohamad, 2017).

The results of research that utilize gamification as a strategy in learning have been investigated by [1] which based on the results of his research stated gamification as a strategy in increasing students' learning motivation by using the web as a platform of the gamification elements used.

There is also research on gamification as a strategy but here is more related to PBL strategy, this research was conducted by [10] which he used Agile Project Management as a medium to improve the effectiveness of learning in the Management study program.

According to [11] in [10] which discusses the position of gamification in learning based on methods and strategies that can use in training and educational processes.

The research method of making gamification interaction design in mobile applications can start by analyzing using gamification design framework (D6) [12]. D6 Framework is a framework for designing forms of gamification. A framework is used in making interaction design because D6 can show the system requirements and the activities carried out using the system in the concept of gamification.

\subsection{Definition of problem based learning}

Problem-Based Learning (PBL) is a learning model by making problems as a starting point for discussion to be analyzed to find solutions or answers by students, usually done in groups, and problem-solving patterns are carried out through stages of the scientific method. According to [13], which states that problem-based learning, is a way to build and learn students based on problems that emerge as a stimulus and focus on student activities.

\subsection{Gamified problem-based learning}

In implementing the effect of PBL-based gamification, this can occur undesirable things because of undeveloped students' insights about the gamification content itself. In the problem identification stage, it is not easy for students to find problems related to the course content if it is associated with the use of gamification as a new strategy in learning. With this level of relevance, as much as possible is associated with experiences and real problems with the lives of students. As for the scope of the problem that can use gamification applications as a strategy in solving their learning problems. Problems related to the course content are given appropriate stimulation and control so that students can know the level of error in understanding the material in the con- text of learning. The mistakes made by the students will cause them to become anx-ious so that as much as possible educators should not interfere too much with the knowledge and experience, they know so that they can then continue the process of learning through problem-based learning. The table below were the element were used in the Gamified Problem Based Learning design and it was adapted from [14]. 
Table 1. Elements of Gamified Problem Based Learning

\begin{tabular}{|l|l|}
\hline \multicolumn{1}{|c|}{ Main Elements } & \multicolumn{1}{c|}{ Definition } \\
\hline Achievements & A specific, defined objective within the game \\
\hline Avatars & A visual representation of a player's character \\
\hline Badges & A visual representation of achievement \\
\hline Leaderboards & Allow the direct comparison of players' expertise \\
\hline Levels & Difficulty moderated based on player expertise \\
\hline Points & Numeric record of players' performance to date \\
\hline Step by Step tutorial & A specific instruction, explore objective within the game \\
\hline Narrative & A specific order to follow \\
\hline Monitoring Bar & A control tools/ Progress helps users understand that their actions, \\
\hline Rewards & A visual representation of a compliment \\
\hline
\end{tabular}

\section{$3 \quad$ Method}

\subsection{Research design}

Research on instructional design models can be classified into three types: model development, model validation, and model use [15]. This study examines the first two points above, which are base on research methodologies for model development and model validation, where learning models are develope either practically or theoretically. In theory, the cause is based on the literature related to the model that is to be developed, being practical because it must be based on a learning design that is suitable for real life. The gamified problem-based learning design model has been based on literature and has projected real-life learning needs.

The following stages of the model being develope can be validated. Validation adjusted for the components in the model and the purpose of the model. The stage of model validation is a process that must consider, this is base in order to be able to provide completeness in the empirical data analysis process and fulfil the initial function practically. The existence of the developed model is seen from the level of validity both internally and externally so that it can help the designer in analyzing each variable from the design stage to evaluating the learning model. The validity of the internal design of a learning model is carried out by experts in the learning model. Medium, the external validity of a product is base on the quality of the product design used by students.

\subsection{Procedure}

Learning design Problem-based learning (PBL) developed refers to the PBL learning design model proposed by [16]. According to these two models, PBL learning design is divide into three stages, namely: 1) input 2) process, and 3) output. This PBL design is guided and supported by theories in learning Gamification and using designs in the catalysis framework [12] as the basis for determining the attractiveness and effectiveness of teaching results. Options for combining gamification and traditional classrooms, optimizing and designing PBL learning assisted by gamification from the student and lecturer side. The design of Gamified problem based learning design carried 
out in the Basic Physics 1 course, Faculty of Teacher Training and Education, Universitas Katolik Widya Mandira - Kupang - NTT - Indonesia. The steps or procedures for the steps or procedures for designing gamified problem based as shown in Figure 1:

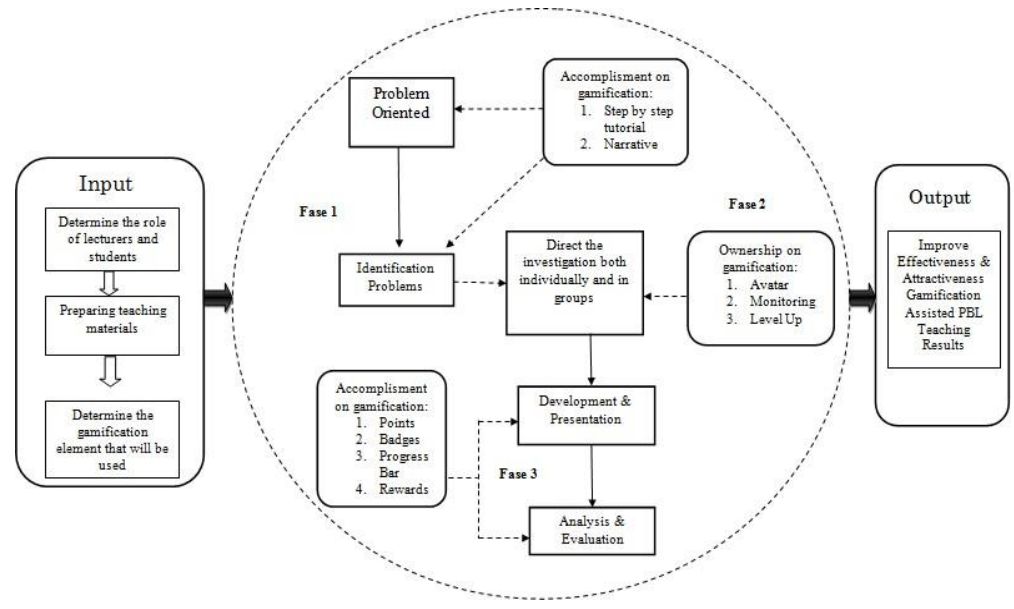

Fig. 1. Gamified Problem Based Learning

\section{Input}

a) Determine the role of lecturers and students, in learning Basic Physics 1, lecturers and students have different roles, but have the same learning goal which is to improve student teaching outcomes in basic Physics courses 1.

b) Preparing teaching materials related to the material. Basic Physics Course 1 uses University level learning modules.

c) Determine the gamification elements that will be used, apart from determining the role of lecturers and students in learning basic physics 1 and preparing teaching materials related to the material, the final part of this input stage is determining what elements will be used in the PBL assisted model gamification. The elements used include step by step

\section{Process}

Phase 1: In learning to use the conventional PBL model, it is necessary to develop a form of the PBL model that uses gamification as a method/technique in learning Basic Physics 1 by using related sources/research. Make an assessment form related to the process and results of PBL aided by Gamification in learning. Basic Physics 1. In this phase several stages in PBL are passed, including: (1) problem-oriented, in this stage students are directed by lecturers to be able to find what problems will discuss in learning Basic Physics 1 according to the material, (2) identify the problem, (3) guide the investigation, both individually and in groups, (4) development and presen- tation, (5) analysis and evaluation 
Phase 2: The process in this phase aims to investigate both individually or in groups in order to improve teaching outcomes on the model for gamification-assisted learning through several steps, include: creating a problem-based learning draft through gamification-assisted PBL models, determining the model analysis tools is use, making an assessment/validation form for lessons learned in problem-based learning through the help of gamification.

Phase 3: Developing and displaying the results of the process of finding and identifying problems that exist in phase 1 then analyzed and evaluated to study the results after the use of PBL learning assisted with gamification both in behaviour patterns, cognitive and affective.

\section{Output}

Producing gamified problem-based learning design that can improve the attractiveness and effectiveness of teaching results.

\subsection{Design validity}

Instrument: The instrument used to validate the gamified problem-based design was a questionnaire with closed-ended and open-ended question types. The closes ended question with a four scale arranged according to the standard questionnaire for the design of e-learning learning [15]. Medium, open-ended questions are used to solicit expert input and suggestions on the design of gamified problem based learning developed.

Data analysis: The data obtained from the gamified problem-based learning design is then classified into 2, namely, quantitative and qualitative data. Quantitative data in the form of scores from each questionnaire that was filled out by learning design experts. While qualitative data contains criticisms and suggestions written by experts for the progress of design development. Analysis techniques are used to determine the extent to which gamified problem-based learning is developed. The scores obtained are then summed and averaged then convention into scores using a scale 4 criterionreferenced test table.

Table 2. Converting Actual Scores to Four Scale Values

\begin{tabular}{ll|c|l|}
\hline No. & Range & Score & Category \\
\hline 1. & $X \geq M i+1 . S b i$ & $X \geq 3$ & Very Good \\
\hline 2. & $M i+1 . S b i>X \geq M i$ & $3>X \geq 2,5$ & Good \\
\hline 3. & $M i>X \geq M i-1 . S b i$ & $3>X \geq 2$ & Less \\
\hline 4. & $X<M i-1 . S b i$ & $X<2$ & Poor \\
\hline $\mathrm{X} \quad=$ Respondent score (score achieved) \\
Mi $=$ Mean ideal = 1/2 (ideal maximum score + ideal minimum score) \\
Sbi $=$ Ideal standard deviation \\
Sbi $=1 / 6$ (ideal maximum score - ideal minimum score) \\
Max Score $=4$ \\
Minimum Score \\
Mi $=1 / 2(4+1)=2.5$ \\
Sbi $=1 / 6(3)=0.5$ \\
$\mathrm{X}=$ actual score
\end{tabular}




\section{$4 \quad$ Result}

\subsection{Pre analysis results}

In this pre-analysis found qualitative data derived from observations, documentation studies and questionnaires filled out by students. The results consist of, (1) learner characteristics, (2) course characteristics, (3) learning environment conditions [15]. The characteristics of the students of Physics, Chemistry and Mathematics Education programs at Widya Mandira Catholic University can be said to have been able to operate all types of mobile devices both on platforms in the form of web/site and android. Students also have personally owned each device, such as a laptop/notebook, cellphone, tablet / iPad. Characteristics of basic Physics 1 courses are subject areas of expertise in physics education study programs. This course is obtained in the first semester, weighing 3 credits ( 1 credit $=50$ minutes) and continuing material in Basic Physics 2 is obtained in the second semester, which course focuses on developing insight and in-depth knowledge of students about theories, laws, principles, and concepts about kinematics, dynamics, effort, energy, power, impulses, and momentum. The condition of the learning environment at the Teaching and Education Faculty of the Universitas Katolik Widya Mandira has been equipped with 1 computer laboratory unit with 35 PCs, and the availability of a WIFI network to connect to the internet both for students and lecturers who are the main supporting facilities in the application of gamified problem-based design this learning at the college level.

\subsection{Final design of gamified problem-based learning}

Continuation of the previous stage is designing a learning design for gamified problem-based learning. Gamified problem-based learning design was developed from the synthesis of gamification and problem-based learning. The resulting learning design matrix illustrates the learning objectives and elements of learning gamification and problem-based learning. In learning objectives refer to bloom's taxonomy, namely remembering (C1), understanding (C2), applying (C3), analyzing (C4), evaluating (C5) and creation (C6). This problem based gamified stage consists of online and offline learning activities. Finally, the gamification features used include achievements, avatars, badges, leaderboard.

\subsection{Validation results}

Learning design experts are validators of this research product. Learning design experts and practitioners provide assessments, comments and revised suggestions relating to aspects of the effectiveness of learning design, Excellence in terms of effectiveness, Attracting objectives on relevance to the desires of students as users, Attractive design of writing questions on Quiz, Attracting student interest as users to find out the contents learning, the convenience of students as users in listening to the contents of learning, the level of speed of time in learning design, the attractiveness of 
learning design display, the accuracy of the composition of animation, colour and text on the interface design, the level of speed and clarity of content, the ease of accessing and operating the navigation on the design, the attractiveness of the composition and layout arrangement in the design of attracting the appearance of the design, easy access and navigation in the learning design, as well as the level of content coherence and message design, effective design of gamified problem-based learning as teaching material in the form of theory and practice $\mathrm{k}$. The results of the assessment of experts and practitioners of learning design on product development are present in the follow- ing table below:

Table 3. Expert and Practitioner Validation Results from Gamified Problem Based Learning Design in Basic Physics Subjects 1

\begin{tabular}{|c|c|c|c|c|c|}
\hline No & Question & Val 1 & Val .2 & Average & Category \\
\hline 1. & Effectiveness of learning design & 4 & 4 & 4 & Very Good \\
\hline 2. & Excellence in terms of learning effectiveness & 3 & 2 & 2,5 & Good \\
\hline 3. & Winning goals on relevance to the wishes of students & 4 & 2 & 3 & Good \\
\hline 4. & The winning design of writing questions on the Quiz. & 3 & 4 & 3,5 & Good \\
\hline 5. & $\begin{array}{l}\text { Attract student interest as users to find out the contents of } \\
\text { learning }\end{array}$ & 4 & 2 & 3 & Good \\
\hline 6. & $\begin{array}{l}\text { The Convenience of students as users in listening to the } \\
\text { contents of learning }\end{array}$ & 3 & 4 & 3,5 & Very Good \\
\hline 7. & The level of speed at which to reach the goal & 4 & 4 & 4 & Very Good \\
\hline 8. & The level of speed and clarity of content & 4 & 4 & 4 & Very Good \\
\hline 9. & Enjoy the appearance of learning design & 3 & 4 & 3,5 & Very Good \\
\hline 10. & Ease of access and operation of navigation on the design & 3 & 2 & 2,5 & Good \\
\hline 11. & $\begin{array}{l}\text { Accuracy in animation, colour and text composition in } \\
\text { interface design }\end{array}$ & 4 & 3 & 3,5 & Very Good \\
\hline 12. & Attractive composition and layout & 4 & 4 & 4 & Very Good \\
\hline 13. & The level of content coherence and message design & 4 & 3 & 3,5 & Very Good \\
\hline 14. & $\begin{array}{l}\text { The effectiveness of design as teaching material in the form } \\
\text { of theory and practice. }\end{array}$ & 4 & 3 & 3,5 & Very Good \\
\hline & Average & 3,6 & 3,2 & & \\
\hline & Average Overall & & & 3,4 & Very Good \\
\hline
\end{tabular}

Based on the data in Table 5 above, it is known that the average score of the whole aspects of the learning design reaches 3.4. This figure according to the table of quantitative data conversion to scale 4 qualitative data belongs to the category of "Very Good", which means that the learning design of gamified problem-based learning developed is feasible to be applied in learning. The recommendations for revision/improvement from learning design experts and practitioners are: 1) in general, the basis of the gamification is more highlighted 2) the design can continued.

\subsection{Discussions}

At the critical learning level, Physics Education Research (PER) has developed knowledge based on the latest "physics learning issues" that will be as profound as the learning abilities of the materials and strategies. Therefore, it is better if educators also begin to direct learning in the classroom to prepare students to become critical learners 
in theorizing and practice. Based on the urgency of the research where the application of gamification, which is assisted by problem-based learning, can become an innovation that can later be applied in a broader learning context and concept.

On the other hand, the basis of student-centred learning according to constructivist theory is in the process of developing the basis of monotonous learning that is transformed into learning that the implementation process is returned to students while the educator is only as a facilitator. The process of identifying several syntaxes is essentially the same. Only a few learning steps will be useful and it does not rule out the use of the syntax in several applications in each institution can be different. The learning syntax in Basic Physics will be develope using eight steps. The syntax developed is as follows: (1) orientation, (2) identifying and analyzing focus data, (3) identifying problems, (4) following temporary hypotheses, (5) exploration, (6) developing collaborative solving interventions, (7) explanation of the results of the hypothesis, (8) Evaluation.

Research [10], which is looked at from the results of systematic mapping in the seven most relevant scientific databases. The process was carried out by filtering empirical data from 2011 to 2014. Which from the conclusions of the study found that there was little empirical research on the effectiveness of gamification in the learning environment, but most of the articles focused on a number of possible game and application mechanisms. in the context of education.

Based on the results of the development of models, designs, strategies and approaches outlined above, there is always a significant change in education in integrating conventional and online learning. If it is understood again, the scenario of combining problem-based learning and gamification learning models in the context of technology will be effective and effective. With new learning designs that synergize with technological developments, students will certainly not only be, but also lecturers who experience boredom in applying conventional learning methods.

\section{Conclusion}

Assessment of the effectiveness of learning design, Excellence in terms of effectiveness, Attractiveness of objectives in relevance to the desires of students as users, Interest in writing question design on Quiz, Attractiveness of student interests as users to find out the learning content, Comfort of students as users in listening to the contents of learning, the level of speed of time in learning design, the attractiveness of the learning design display, the accuracy of the composition of animation, colour and text on the interface design, the level of speed and clarity of content, the ease of accessing and operating the navigation in the design, the interesting composition and arrangement of layouts in the design of the attractiveness of the display design, the ease of accessing and navigating in learning design, as well as the level of content coherence and message design, effective design of gamified problem-based learning as teaching material in the form of theory and practice have shown results in the "very good" category which means this learning design has been feasible to be applied in learning. 


\section{$6 \quad$ References}

[1] Seliro Wangi. N. B., Setyosari. P., Kuswandi. D., Dwiyogo. W.D. 2018. Gamification as a Strategy to Improve Student Learning Motivation: Preparing Student for 21st Century. International Journal of Engineering \& Technology, 7 (2.14) (2018) 323-325.

[2] McGonigal, J. (2011). Reality is broken: Why games make us better and how they can change the world. London: Penguin.com.

[3] Turan. T., Avinc. Z., Kara. K, Goktas. Y., (2016). Gamification and Education: Achievements, Cognitive Loads, and Views of Students. International Journal of Emerging Technologies in Learning, iJET - Vol. 11(7). Retrieved From https://doi.org/10.3991/ijet. $\underline{\mathrm{v} 11 \mathrm{i} 07.5455}$

[4] Leaning, Marcus. 2015. A study of the use of games and gamification to enhance student engagement, experience and achievement on a theory-based course of an undergraduate media degree. School of Media and Film, University of Winchester, Winchester, UK. https ://doi.org/10.1080/14682753.2015.1041807

[5] Bicen. H., Kocakoyun. S., (2018). Perceptions of Students for Gamification Approach: Kahoot as a Case Study. International Journal of Emerging Technologies in Learning . iJET - Vol. 13(2). Retrieved From https://doi.org/10.3991/ijet.v13i02.7467

[6] Stott, A., \& Neustaedter, C. (2013). Analysis of gamification in education, (TR 2013- 042201). Connections Lab, Simon Fraser University, Surrey, BC, Canada. Retrieved from: http://carmster.com/clab/uploads/Main/Stott-Gamification.pdf

[7] Deterding. (2011). From game design elements to gamefulness: defining "gamification". Proceedings of the 15th International Academic MindTrek Conference: Envisioning future media environments, (page 9-15). https://doi.org/10.1145/2181037.2181040

[8] Zhuhadar, L. (2016). Applicative Personalized Learning: How Gamification is Driving Learning. International Journal of Knowledge Society Research, 24-27. https://doi.org/10. 4018/ijksr.2016100103

[9] Hung, A. C. (2017). A Critique and Defense of Gamification. Journal of Interactive Online Learning.

[10] Oliveira, J. (2016), The Effectiveness Of Gamification As A Problem-Based Learning Tool On Teaching Agile Project Management. The University of Liverpool. Dissertation.

[11] Kapp, K.M. (2012). The gamification of learning and instruction: Case-based methods and strategies for training and education. New York, NY: Pfeiffer.

[12] Werbach. (2012). For The Win: How Game Thinking Can Revolutionize Your Business. Philadelphia: Wharton Digital Press.

[13] Boud, D., Feletti. \& Grahame I. 1997. The Challenge of Problem-based Learning (2nd Edition). London: Designs and Patents Act.

[14] Buckley, Patrik, Doyle, Elaine. (2016). Individualising gamification: An investigation of the impact of learning styles and personality traits on the efficacy of gamification using a prediction market. Kemmy Business School, University of Limerick, Limerick, Ireland. Retrieved From https://doi.org/10.1016/j.compedu.2016.11.009

[15] Suartama, I. K., Setyosari, P., Sulthoni, \& Ulfa. S. (2019). Development of an Instructional Design Model for Mobile Blended Learning in Higher Education. International Journal of Emerging Technologies in Learning. iJET - Vol. 14(16), 4-22. Retrieved from https://doi. org/10.3991/ijet.v14i16.10633

[16] Phungsuk, R., Viriyavejakul, C., Ratanaolarn, T. (2017) Development of A Problem-Based Learning Model via A Virtual Learning Environment. Kasesart Journal of Social Sciences 38 (2017) 297-306. Retrieved From http://www.elsevier.com/locate/kjss https://doi.org/10. 1016/j.kjss.2017.01.001. 


\section{$7 \quad$ Acknowledgement}

This study was supported by BPPDN scholarship from the Ministry of Research, Technology, and Higher Education of the Republic of Indonesia

\section{Authors}

Isabel Coryunitha Panis is a doctoral student at the Universitas Negeri Malang, Malang, Indonesia. She is also currently teaching an instructional lesson at Universitas Katolik Widya Mandira, Kupang, Indonesia. Her research interests are e-learning, gamification learning, and problem-based learning.

Punaji Setyosari is a professor in the postgraduate program of Department of Education and Technology at the Universitas Negeri Malang, Malang, Indonesia. His research interests include research methodologies, evaluation and assessment, instructional media, problem-based learning, and collaborative learning

Dedi Kuswandi is a lecturer in the Department of Educational Technology at the Universitas Negeri Malang, Malang, Indonesia. His research interests include instructional media and learning strategies.

Lia Yuliati is a lecturer in the Department of faculty of mathematics and natural education at the Universitas Negeri Malang, Malang, Indonesia. Her research interests include learning strategies.

Article submitted 2020-02-27. Resubmitted 2020-03-30. Final acceptance 2020-03-30. Final version published as submitted by the authors. 